PREPARED FOR THE U.S. DEPARTMENT OF ENERGY, UNDER CONTRACT DE-AC02-76CH03073

PPPL-3950

PPPL-3950

UC-70

Compact Probe for Power Detection from the Narrow Side of the Waveguide

by

C.C. Kung, S. Bernabei, J. Gumbas, N. Greenough, E. Fredd, J.R. Wilson, and J. Hosea

May 2004

NM|

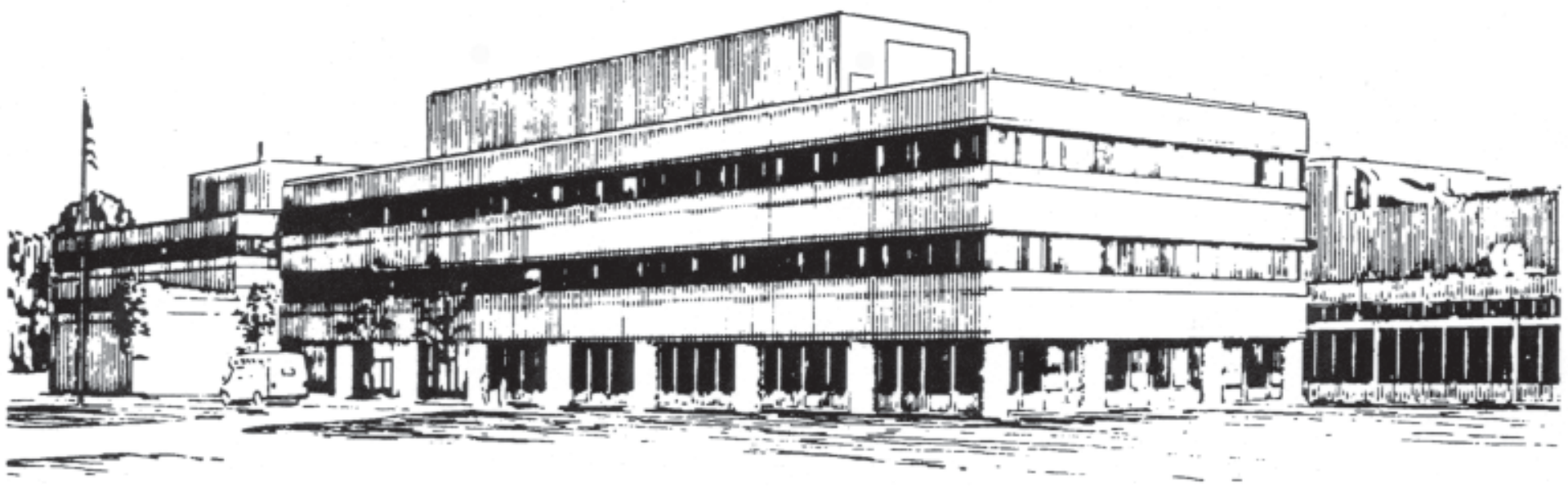

PRINCETON PLASMA PHYSICS LABORATORY PRINCETON UNIVERSITY, PRINCETON, NEW JERSEY 


\section{PPPL Reports Disclaimer}

This report was prepared as an account of work sponsored by an agency of the United States Government. Neither the United States Government nor any agency thereof, nor any of their employees, makes any warranty, express or implied, or assumes any legal liability or responsibility for the accuracy, completeness, or usefulness of any information, apparatus, product, or process disclosed, or represents that its use would not infringe privately owned rights. Reference herein to any specific commercial product, process, or service by trade name, trademark, manufacturer, or otherwise, does not necessarily constitute or imply its endorsement, recommendation, or favoring by the United States Government or any agency thereof. The views and opinions of authors expressed herein do not necessarily state or reflect those of the United States Government or any agency thereof.

\section{Availability}

This report is posted on the U.S. Department of Energy's Princeton Plasma Physics Laboratory Publications and Reports web site in Fiscal Year 2004. The home page for PPPL Reports and Publications is: http://www.pppl.gov/pub_report/

DOE and DOE Contractors can obtain copies of this report from:

U.S. Department of Energy

Office of Scientific and Technical Information

DOE Technical Information Services (DTIS)

P.O. Box 62

Oak Ridge, TN 37831

Telephone: (865) 576-8401

Fax: (865) 576-5728

Email: reports@adonis.osti.gov

This report is available to the general public from:

National Technical Information Service

U.S. Department of Commerce

5285 Port Royal Road

Springfield, VA 22161

Telephone: $1-800-553-6847$ or

(703) $605-6000$

Fax: (703) 321-8547

Internet: http://www.ntis.gov/ordering.htm 


\title{
COMPACT PROBE FOR POWER DETECTION FROM THE NARROW SIDE OF THE WAVEGUIDE
}

\author{
C. C. Kung, S. Bernabei, J. Gumbas, N. Greenough, E. Fredd, J. R. Wilson, J. Hosea \\ Princeton Plasma Physics Laboratory, Princeton University \\ P.O. Box 451, Princeton, New Jersey, 08543
}

\begin{abstract}
Phased array antennas with high directivity have a variety of applications. One of their applications is in RF heating for magnetically confined plasma fusion research. Among these RF heating schemes, waveguide arrays with careful phase control on each waveguide can act as a phased array antenna to deliver megawatts of power for heating fusion plasmas in the lower-hybrid range of frequencies $(1 \mathrm{GHz}-10 \mathrm{GHz})$. In order to achieve compactness, it is common to stack reduced height waveguide together to form the waveguide array. As long as the delivered power does not cause arcing in the waveguide, the waveguide height can be quite small. Due to this confined space in a stack of reduced height waveguides, power detection of the incident and reflected wave in the reduced height waveguide is extremely difficult. A new compact probe, which employs current loops, to monitor the incident and reflected wave from the narrow side of the reduced height waveguide has been developed. Its theory and performance will be reported in this paper.
\end{abstract}




\section{INTRODUCTION}

It has been proven that lower hybrid current drive (LHCD) is the most efficient noninductive method for driving currents in tokamaks. This is of great importance for future fusion reactor design. At present, PPPL and MIT are preparing an experiment on current profile control by using Lower Hybrid waves at $4.6 \mathrm{GHz}$ at power levels up to a few megawatts to produce and sustain advanced tokamak regimes in near steady state conditions in Alcator C-Mod. Since the controlled current profile is delivered by using a waveguide array[1], a stack of reduced height waveguides with proper phase control on each waveguide to form a phase array antenna will be utilized. Of course, this type of waveguide array can also be used in a radar system for communication or imaging. However, there is always some technical difficulty in monitoring the power flowing through the reduced height waveguide[2], [3]. This is because the wide side of the waveguide is inaccessible to a conventional E-probe. To overcome this problem, a new compact probe was designed by using current loops to sample a small portion of the $H_{z}$ field in the $\mathrm{TE}_{10}$ mode. Due to the spatial profile of the $H_{z}$ field in the $\mathrm{TE}_{10}$ mode, the maximum field strength is at the narrow sidewall of the reduced height waveguide[4]. Thus, the best position to place the current loop is at the narrow side of the reduced height waveguide so that the maximum loop efficiency can be achieved. In the following, the theory and some test results for the compact probe using current loops will be described. 


\section{THEORY}

In this section, the basic physics for those three components (current loop, directional coupler, and phase shifter), which constitute the compact probe, will be described. The overall effect of putting together those three components will be discussed at the end of this section.

\section{A. Current Loop}

The current loop itself is a short length of semi-rigid cable. One end of the cable is attached to a male SMA connector while at the other end the center conductor is connected to the outer conductor forming a small loop. In terms of $\mathrm{TE}_{10}$ mode in a waveguide with the cross-section dimensions of $a$ and $b$, the $\mathrm{H}$-field in the z-direction and E-field in the y-direction can be expressed as

$$
\begin{aligned}
& H_{z}=H_{O} \operatorname{Cos}(\pi x / a) e^{j(\omega t-k z)}, \\
& E_{y}=E_{O} \operatorname{Sin}(\pi x / a) e^{j(\omega t-k z)}=-j \omega \mu_{o}\left(\frac{a}{\pi}\right) H_{O} \operatorname{Sin}(\pi x / a) e^{j(\omega t-k z)},
\end{aligned}
$$

where $\omega=2 \pi f$ is the angular frequency, $f$ is the frequency, and $\mu_{o}$ is the permeability in free space[4]. Due to the spatial distribution profile of the $H_{z}$ field in the $\mathrm{TE}_{10}$ mode, the current loop samples a small portion of the $H_{z}$ field in the $\mathrm{TE}_{10}$ mode. Since the current loop is at the edge of the waveguide wall in this application $\left(x \approx 0\right.$ in Eq. (1)), the $H_{z}$ field in this case is uniform and equal to $H_{O}$ across the loop. According to Faraday's law, the induced voltage, $V_{L}$, across the center conductor and the outer conductor can be expressed as

$$
V_{L}=-j \omega \int \mu_{0} H_{O} \hat{a}_{z} \cdot\left(-\hat{a}_{z}\right) d A=j \omega \mu_{0} H_{O} A=j \omega L I_{L},
$$

where $A$ is the loop intercepting area perpendicular to the $H_{z}$ field, $L$ is the effective 
inductance, and $I_{L}$ is the induced current. In this case, the current loop can be treated as an inductance with an induced current $I_{L}$ and the equivalent circuit will be an ideal current source in parallel with the inductance. Because the area $A$ is very small, the inductance value and the effective loop impedance will be extremely low. Thus the power, $P_{L}$, being sampled by the current loop can be estimated by

$$
P_{L}=\left|V_{L}\right|^{2} / 2 Z_{O}=\omega^{2} \mu_{0}{ }^{2} H_{O}{ }^{2} A^{2} / 2 Z_{O},
$$

where $Z_{O}$ is the characteristic impedance of the probe system. The transmitted power, $P_{T}$, in the waveguide for $\mathrm{TE}_{10}$ mode is

$$
P_{T}=E_{O}{ }^{2} a b / 4 Z_{T E 10}=\frac{\omega^{2} \mu_{0}{ }^{2} a^{3} b H_{O}{ }^{2}}{480 \pi^{3}} \sqrt{1-(c / 2 a f)^{2}},
$$

where $c$ is the speed of light in free space. The coupling ratio for the current loop can be determined by

$$
\frac{P_{L}}{P_{T}}=\frac{240 \pi^{3} A^{2}}{a^{3} b Z_{O} \sqrt{1-(c / 2 a f)^{2}}} .
$$

Normally, the power that flows through the reduced height waveguides can be as high as a few tens of kilowatts in the LHCD experiment. The coupling ratio should be less than $-40 \mathrm{~dB}\left(10^{-4}\right)$. Hence, the required loop area $A$ is $5.4 \times 10^{-3} \mathrm{~cm}^{2}$ when using $a=4.755 \mathrm{~cm}, b=0.554 \mathrm{~cm}, Z_{O}=50 \Omega$, and $f=4.6 \mathrm{GHz}$ in Eq. (6). Because the loop area is less than $1 \mathrm{~mm}^{2}$, it can be easily achieved by bending the cable center conductor and soldering it directly to the outer conductor. If the coupling ratio is still too strong with this loop area, the effective loop intercepting area perpendicular to the $H_{z}$ field can be reduced by rotating and/or adjusting the penetration depth of the current loop. 


\section{B. Directional Coupler}

The physical structure of a TEM mode directional coupler is a pair of transmission lines adjacent to each other in close proximity. The interaction length, $l$, of these two transmission lines is an odd multiple of quarter wavelength of the desired frequency, $f$, e.g. $(2 \mathrm{n}+1) \lambda / 4$, where $\mathrm{n}=0,1,2 \ldots$ and $\lambda$ is the wavelength in the transmission line. The coupling value of the directional coupler depends on the separation distance. The smaller the separation distance is, the tighter the coupling value is. The bandwidth of the directional coupler for $\mathrm{n}=0$ (Fig. 1), which still satisfies the desired coupling value and phase shift, is usually more than $10 \%$ of the desired coupling frequency.

As shown in Fig. 1, the TEM wave propagating into Port 1 along the transmission line in the interactive region can be decomposed into an even mode and odd mode[5]. When the injected wave and the induced wave are of the same voltage polarity, it is called even mode. When the injected wave and the induced wave are of the opposite voltage polarity, it is called odd mode. By using the transmission line equations for the even mode and the odd mode and then forcing the boundary conditions to be matched loads at these 4 ports, following equations can be derived:

$$
\begin{aligned}
& \text { Port } 1=1 \\
& \text { Port } 2=\frac{\sqrt{1-k^{2}}}{\sqrt{1-k^{2} \operatorname{Cos} \theta+j \operatorname{Sin} \theta}} \\
& \text { Port } 3=\frac{j k \operatorname{Sin} \theta}{\sqrt{1-k^{2}} \operatorname{Cos} \theta+j \operatorname{Sin} \theta} \\
& \text { Port } 4=0
\end{aligned}
$$

where $k$ is the voltage wave coupling coefficient and $\theta=2 \pi / \lambda$ is the electrical angle of the interaction length. For $l=\lambda / 4$, Port 2 in Eq. (8) becomes $-j \sqrt{1-k^{2}}$ and Port 3 in Eq. 
(9) becomes $k$. The induced wave is propagating out of Port 3. This kind of backward propagation at the coupling port can be intuitively understood as follows for the coaxial transmission line. The $E$-field of the fundamental TEM mode in the coaxial transmission line is in the radial direction. The coupling line in this case behaves like a receptacle to terminate the $E$-field. This implies that the odd mode has more profound effect on the coupling mechanism. Meanwhile the $H$-field is in the angular direction circulating around the center conductor. Because the coupling line does not strongly perturb this $H$ field at all, the $H$-field around the coupling line will not alter its direction. Thus, the $E$ field is of the opposite direction and the $H$-field is of the same direction at the coupling line. In terms of the Poynting vector $(E \times H)$, the propagation direction of the TEM wave at the coupling line is opposite to that of the main line. As can be seen clearly when $l$ $=\lambda / 4$, the coupling port (Port 3$)$ does not introduce any phase change and the direct port (Port 2) does introduce $90^{\circ}$ phase change. In general, the coupling value of a directional coupler is usually shown in terms of $-20 \log (k) \mathrm{dB}$.

\section{Phase Steering}

The phase shifter, in fact, can be as simple as a trimmer capacitor, $C$, which is inserted into a transmission line. As shown in Fig. 2, the transmission line is terminated with matched loads at both ends. In terms of transmission line theories, these two matched loads can be transferred to the vicinity of the capacitor disregarding the length of the transmission lines on both sides of the capacitor.

By using the ac network analysis, it can be found that

$$
\frac{V_{\text {out }}}{V_{\text {in }}}=\frac{Z_{O}}{\sqrt{Z_{O}^{2}+1 / \omega^{2} C^{2}}} \angle \tan ^{-1}\left(1 / \omega C Z_{O}\right),
$$


where $Z_{O}$ is the matched load/characteristic impedance. This indicates that the output voltage waveform to the input voltage waveform is changed by $\tan ^{-1}\left(1 / \omega C Z_{O}\right)$ through this capacitive network. The voltage standing wave ratio, VSWR, due to this capacitive network can be calculated by

$$
V S W R=\sqrt{1+1 / \omega^{2} Z_{O}^{2} C^{2}} .
$$

For example, if $1 / \omega C=Z_{O}=50 \Omega$ in a $50 \Omega$ transmission line system, the introduced phase change from Eq. (11) will be $45^{\circ}$ and the VSWR in Eq. (12) will become $1.4: 1$. This VSWR corresponds to $15-\mathrm{dB}$ return loss. In other words, it is possible by using this simple circuit structure to obtain enough phase shift without severely deteriorating the system return loss. At $4.6 \mathrm{GHz}$, the capacitance value for this network is $0.7 \mathrm{pF}$.

\section{Probe Assembly}

As mentioned earlier, the coupling port of the directional coupler introduces $0^{\circ}$ phase shift and the direct port introduces $90^{\circ}$ phase shift. When these two current loops are connected to the coupling port (Port 3) and output port (Port 2) of the coupler respectively, the phase difference becomes either $0^{\circ}$ or $180^{\circ}$ at one of the ports of the directional coupler depending on the propagation direction of the wave in the waveguide. This basic concept of obtaining good directivity is illustrated in Fig. 3(a) and (b).

In Fig. 3(a), the power detector will not detect any power as long as the combined waves are equal in amplitude but $180^{\circ}$ out of phase. However, the combined waves at the $50 \Omega$ dummy load will not be equal in amplitude if the directional coupler is other than a 3-dB coupler. This indicates that the $50 \Omega$ dummy load absorbs more direct power than coupling power in this case. On the other hand, the power detector will detect the power 
as shown in Fig. 3(b) due to the same amplitude and phase of the combined waves. Even though the combined waves are out of phase at the dummy load, their amplitudes are not equal if the coupler is not a $3-\mathrm{dB}$ coupler. Thus the dummy load still has to absorb some power under this condition. This implies that the $50 \Omega$ dummy load plays a very important role in providing good directivity for this compact probe. If this dummy load fails during the operation, the compact probe directivity will disappear.

In order to match the coupling value of the directional coupler, the coupling value of the current loop connected to the output port has to be reduced accordingly by decreasing the intercepting area. This is achieved through rotating and/or adjusting the penetration depth of the current loop. Since machining error is inevitable, a trimmer capacitor, which is used as a phase shifter, is attached to one of the current loops to compensate for phase error. Due to the low desired coupling value from the waveguide $(<-40 \mathrm{~dB})$, the loop area has to be as small as possible. This suggests that the loop impedance be very low. Even though this low impedance might cause some mismatch to the rest of the system, the directional coupler will function as a buffer and alleviate the mismatch problem.

\section{TEST SETUPS}

\section{A. Reduced Height Waveguide}

Fig. 4 shows a single layer of reduced height waveguide that is made of aluminum. The main part of the reduced height waveguide is a piece of long rectangular aluminum strip whose center is milled away to produce a groove that is 1.872 " wide and 0.218 " deep. A matched aluminum plate is machined and is bolted on top of this groove 
to form a reduced height waveguide. In order to provide good contact between these two pieces, 5 machine screws are used along each side to firmly fasten them together.

Two 4" long tapers are used to gradually transit the reduced height waveguide size to standard WR187 waveguide at both ends of the reduced height waveguide. Two standard WR187 to N-type connector adaptors are attached to the tapers to facilitate the measurement with a network analyzer.

\section{B. Test Equipment}

An Agilent 8753ES network analyzer was used for taking the test data. Since the frequency of the C-Mod LHCD experiment is at $4.6 \mathrm{GHz}$, the network analyzer was set up to sweep from $4.2 \mathrm{GHz}$ to $5.0 \mathrm{GHz}$. The internal power level and the IF bandwidth of the network analyzer were set at $0 \mathrm{dBm}$ and $300 \mathrm{~Hz}$ respectively to insure adequate dynamic range for the measurement. The primary parameter of interest is $S_{21}$ for most of the measurements. Hence, the network analyzer was constantly calibrated and checked with an N-type female-female adaptor to assure the measurement accuracy and repetability.

IV. TEST RESULTS AND CONCLUSIONS

\section{A. Typical Test Results}

In order to verify the theories, a lab-fabricated $10-\mathrm{dB}$ coupler was built using microstrip lines. The substrate material for this directional coupler is Duroid 5880 from Rogers Corporation. Its dielectric constant is $\varepsilon_{\mathrm{r}}=2.2$. Since an X-Acto knife was used to cut out the excess copper from the substrate to form the microstrip lines, the unevenness of the lines and their adjacent substrates detrimentally affected the directivity of the 
prototype directional coupler. The measured directivity is $\sim 5 \mathrm{~dB}$ at $4.6 \mathrm{GHz}$ for this labfabricated 10-dB coupler. The measured value for the output port (Port 2) with a matched cable is $-0.94 \mathrm{~dB}$ at $4.6 \mathrm{GHz}$ and for the coupling port (Port 3) with a trimmer capacitor is $-11.96 \mathrm{~dB}$ at $4.6 \mathrm{GHz}$. The maximum value of the trimmer capacitor is $5 \mathrm{pF}$. The overall assembly for this compact probe is shown in Fig. 5.

As shown in Fig. 5, current loop 1 was connected to the coupling port (Port 3) of the coupler and current loop 2 was connected to the output port (Port 2) of the coupler. The trimmer capacitor was adjusted to obtain the optimal phase shift, and then the coupling values from these two current loops were slightly adjusted through gentle pulls and/or twists. As shown in Fig. 6(c), the directivity is greater than $35 \mathrm{~dB}$ at $4.6 \mathrm{GHz}$ when the coupling value for the forward path is $-34.3 \mathrm{~dB}$ at $4.6 \mathrm{GHz}$ and for the reverse path is $-73.8 \mathrm{~dB}$ at $4.6 \mathrm{GHz}$. In fact, the results shown in Fig. 6(a) and (b) were measured after the optimal result was obtained. The coupling values at $4.6 \mathrm{GHz}$ were $-34 \mathrm{~dB}$ for current loop 1 (Fig. 6(a)) and $-38.8 \mathrm{~dB}$ for current loop 2 (Fig. 6(b)) respectively. Because of the resonant effect from the trimmer capacitor in this case, current loop 1 is $6 \mathrm{~dB}$ lower than the expected value $(\sim 28 \mathrm{~dB})$ and the difference between these two coupling values from current loop 1 and current loop 2 is less than $10 \mathrm{~dB}$. Two other directional couplers were also used in this experiment. One is a commercially available 3-dB coupler for 4-6 GHz from Merrimac and the other is a lab-fabricated 20$\mathrm{dB}$ coupler. This lab-fabricated coupler was made by merely soldering two semi-rigid coaxial cables together with an interaction region of a quarter wavelength. Due to the dielectric material in the semi-rigid coaxial cable, the interaction region in this case is 
about $1.1 \mathrm{~cm}$. Similar results of greater than $35-\mathrm{dB}$ directivity at $4.6 \mathrm{GHz}$ were obtained with these two directional couplers.

In terms of using the 3-dB coupler, both current loops are set up to sample the same power level. Hence the coupling port and the direct port of the coupler can be used to detect the forward and reverse power simultaneously as long as both ports are well terminated with the matched impedances (50 $\Omega$ in this design). Because of the short development time and relatively small quantity, a Merrimac 3-dB coupler and a Weinschel phase shifter are selected to build the compact probe (Fig. 7) for this MIT LHCD experiment. In order to facilitate the installation, current loop 1 is 2 " long and loop 2 is 5.28 " long. When loop 1 is attached to the Weinschel phase shifter through an SMA male-male adaptor, the length difference between loop 1 and loop 2 is exactly half wavelength $(0.9 \mathrm{in})$ in this semi-rigid coaxial cable.

Because the directional coupler can be designed with microstrip lines or strip lines crossing each other on both sides of the dielectric substrate, the direct port and the coupling port can be on the same side of the coupler as most of the commercial coupler designs. In this case, the integrated microstrip/strip line design will be the most economical in cost and the most compact in size, especially when a large quantity is required for this type of experiment such as LHCD in Tore Supra when large number of reduced height waveguides coupler would be required.

\section{B. Conclusions}

Basic theories and some test data for this new compact probe have been presented in this paper. Since a current loop placed on the narrow side of the waveguide is intercepting the $H_{z}$ field, it changes the $\mathrm{TE}_{10}$ mode to TEM mode while coupling a 
fraction of power from the waveguide. Because the desired coupling fraction is very low, the current loop area has to be as small as possible. However, the current loop does not introduce adverse mismatch to the system. This is due to the directional coupler, which acts as a buffer to alleviate this mismatch problem. In addition, a good matched load at the power detector end of the coupler will further reduce any mismatch problems from the current loops.

Test results show that there is no measurable mismatch to the waveguide when the current loop is inserted and the coupling value can be modified by adjusting the penetration depth of the current loop or by rotating it. When using two current loops with $\lambda \mathrm{g} / 4$ spacing and a TEM mode directional coupler, a very high directivity can be achieved. Test results show that the highest directivity can be tuned to $4.6 \mathrm{GHz}$ when a small trimmer capacitor is introduced in one of the current loops for phase adjustment. The initial phase change of the trimmer capacitor when set to its middle point should be taken into account in order to expedite the final adjustment. By matching the coupling values from these two current loops with the directional coupler, $30 \mathrm{~dB}$ to $40 \mathrm{~dB}$ directivity was obtained at $4.6 \mathrm{GHz}$ during the test.

Test results also indicate that the directional coupler does not have to be of very high quality so long as the phase and amplitude match at the output port. Directional coupler can use strip line or microstrip line design to obtain tighter coupling values (such as 3-dB) so as to reduce the amplitude mismatch at the dummy load end; thus the burden for the $50 \Omega$ dummy load on the directional coupler can be reduced. If the dummy load failed during the test, the directivity for the compact probe system would disappear. 
At present, current loops are manufactured by bending the center conductor and soldering directly to the outer conductor. This method provides the smallest aperture area and thus the coupling values are the lowest and they are more constant from loop to loop.

\section{ACKNOWLEDGMENT}

We would like to thank Mr. G. D. Loesser and Mr. J. Rushinski for designing the mock-up reduced height waveguide and the tapers. This work was supported by US DOE Contract No. DE-AC02-76CH03073 and US DOE Cooperative Agreement DEFC02-99ER54512.

\section{REFERENCES}

[1] J. E. Stevens, R. E. Bell, S. Bernabei, A. Cavallo, T. K. Chu, P. L. Colestock, W. Hooke, J. Hosea, F. Jobes, T. Luce, E. Mazzucato, R. Motley, R. Pinsker, S. Von Goeler, J. R. Wilson, “Lower Hybrid Experiments on PLT Using Grills with Various $\mathrm{n}_{\|}$Spectral Widths", Nuclear Fusion, Vol. 28, No. 2 (1988), pp. 217-230.

[2] Ph. Bibet, J. Achard, G. Berger By, M. Goniche, R. Magne, J. J. Capitain, G. Rey, G. Tonon, X. Litaudon, and D. Moreau, "Scattering Matrix of Tore Supra Lower Hybrid Antenna", Association Euratom-C. E. A., EUR-CEA-FC-1390, March 1990.

[3] P. Jacquet, Y. Derners, G. A. Chaudron, V. Glaude, A. Côté, A. Dubé, R. Mireault, A. Robert, and L. Vachon, "Microwave probe diagnostic for the lower hybrid multijunction antenna on TdeV”, Rev. Sci. Instrum. 68 (2), Feb. 1997, pp.1176-1182.

[4] S. Ramo, J.R. Whinnery, and A. VanDuzer, "Fields and Wave in Communication Electronics", $3^{\text {rd }}$ edition, John Wiley \& Sons, Inc., 1994, pp. 417-428. 
[5] G. Matthaei, L. Young, and E. M. T. Jones, "Microwave Filters, Impedance-Matching Networks, and Coupling Structures", reprinted by Artech House, 1980, Chapter 13. 


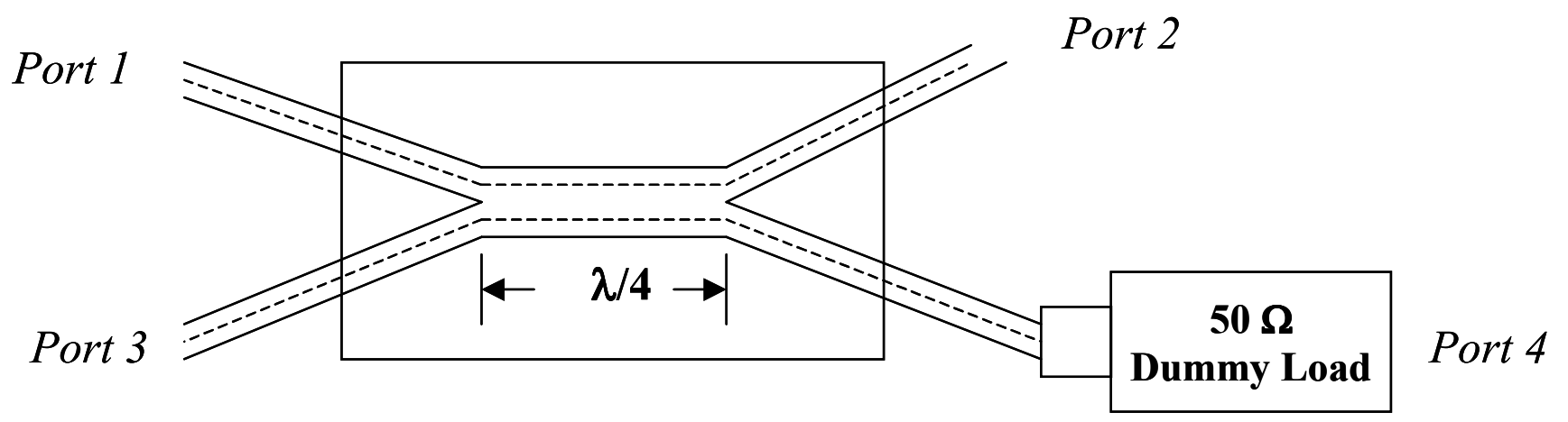

Fig. 1. Directional coupler for $n=0$ 


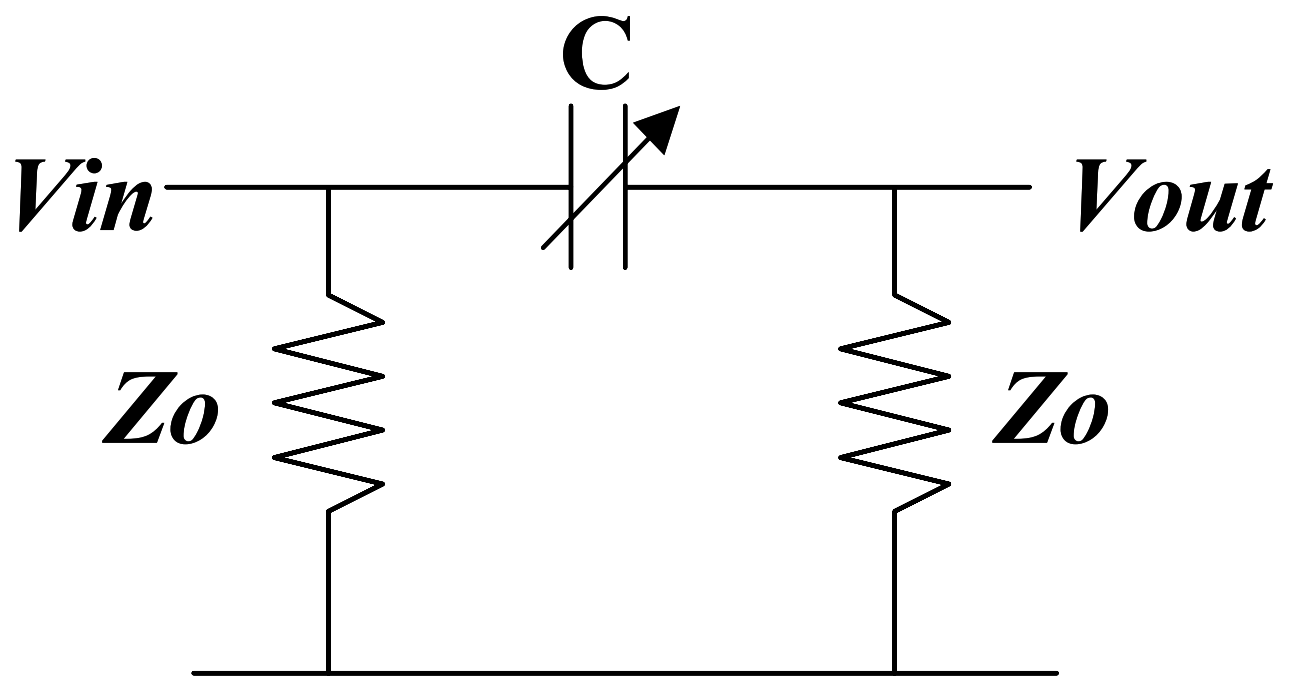

Fig. 2. A simple phase shifter by using a trimmer capacitor 


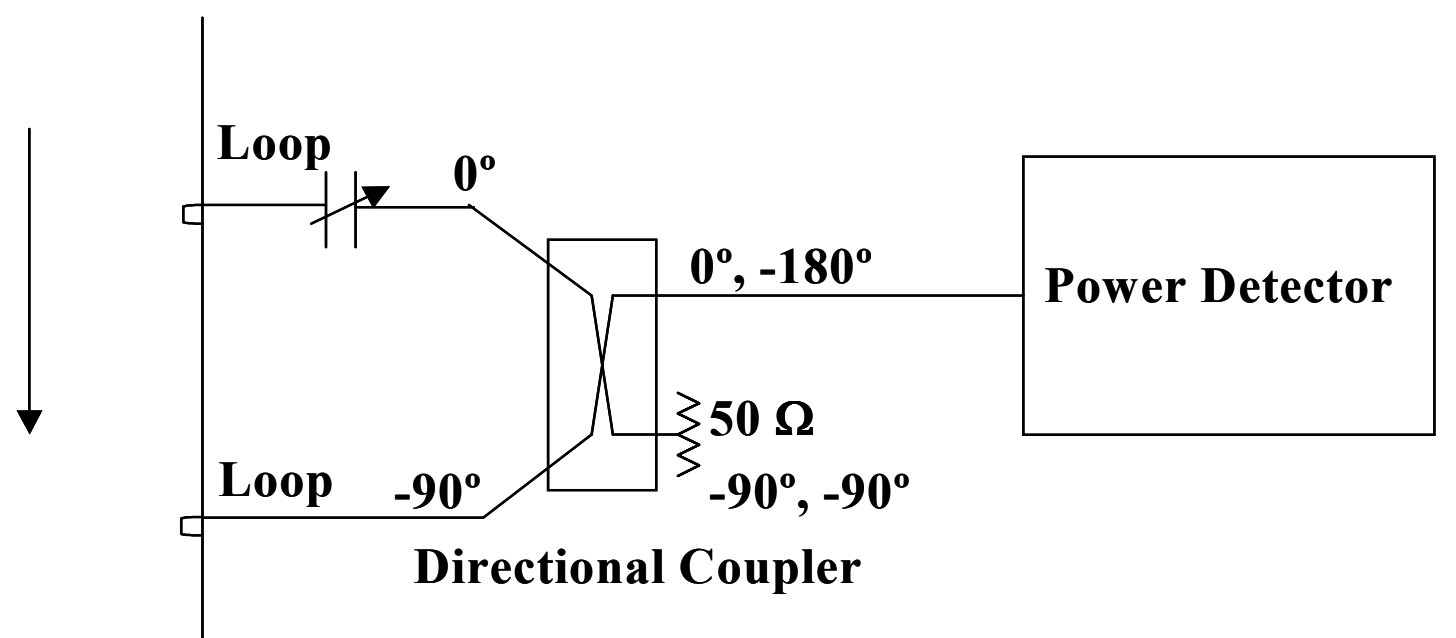

\section{Reverse Direction}

(a)

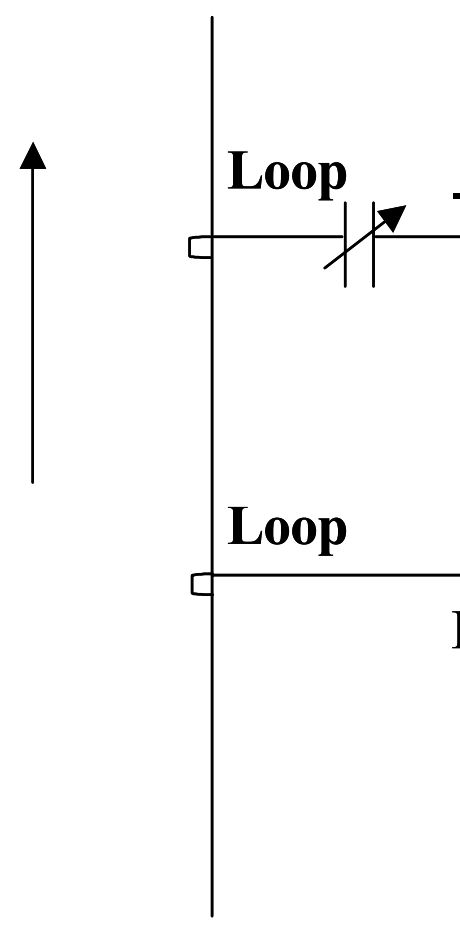

\section{Forward Direction}

(b)

Fig. 3(a): The microwave power at the power detector is out of phase. No power will be detected. The in-phase power will be absorbed by the $50 \Omega$ dummy load. (b): The microwave power at the $50 \Omega$ dummy load is out of phase. No power will be absorbed. The in-phase power will appear at the power detector. 


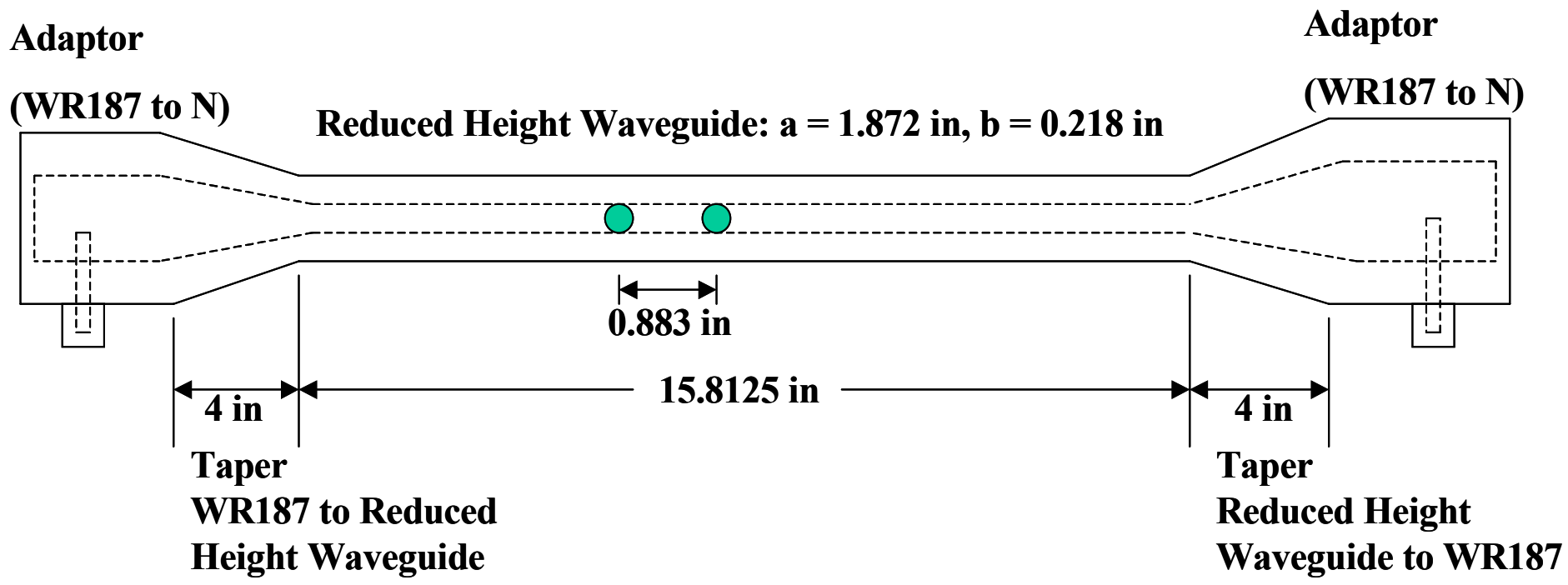

Fig. 4. Test setup and reduced height waveguide dimensions 


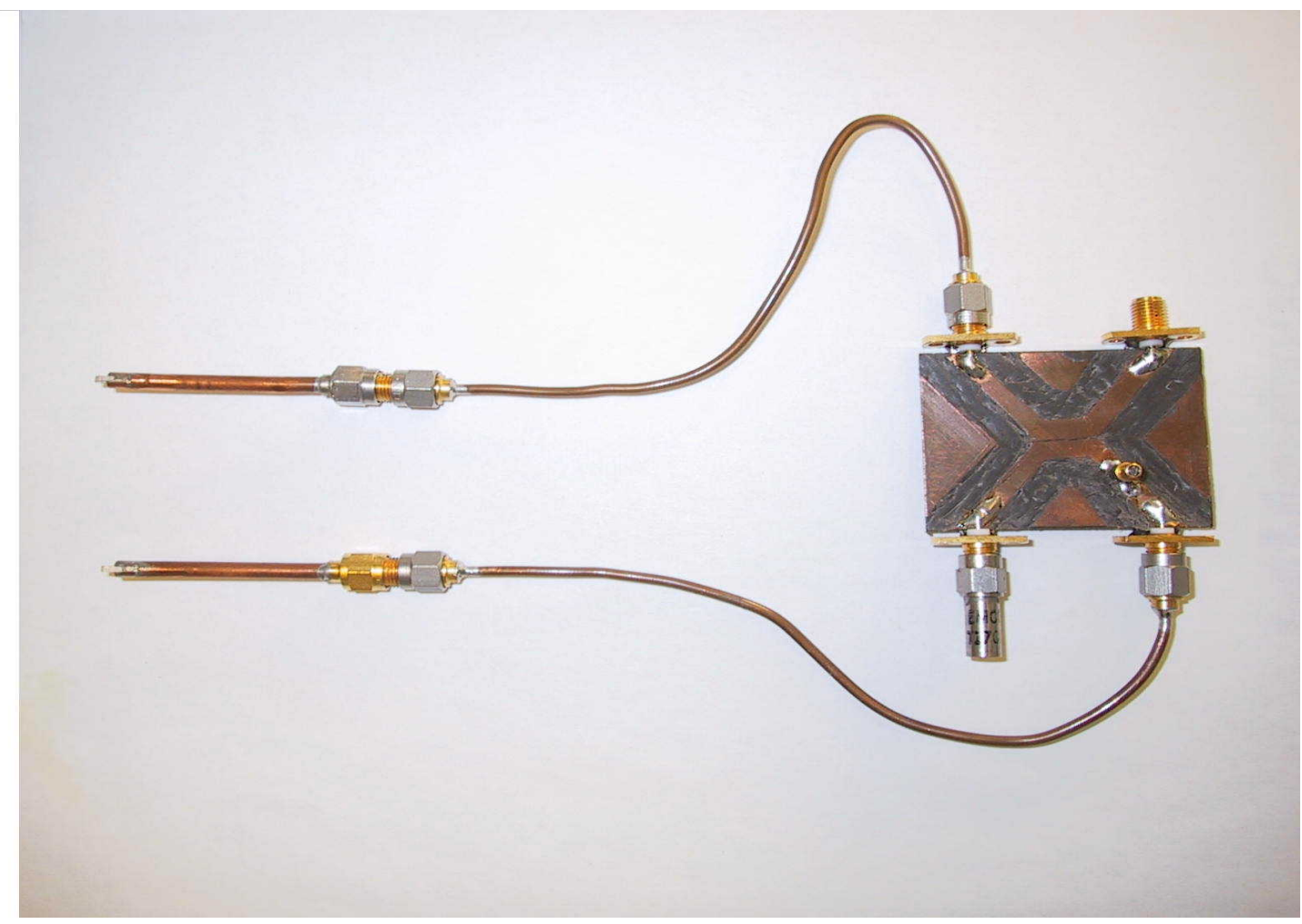

Fig. 5. The lab-fabricated 10-dB directional coupler with a 5-pF trimmer capacitor at the coupling port is used for the compact probe. Current loop 1 is connected to the coupling port (Port 3) of the coupler and current loop 2 is connected to the direct port (Port 2) of the coupler. 


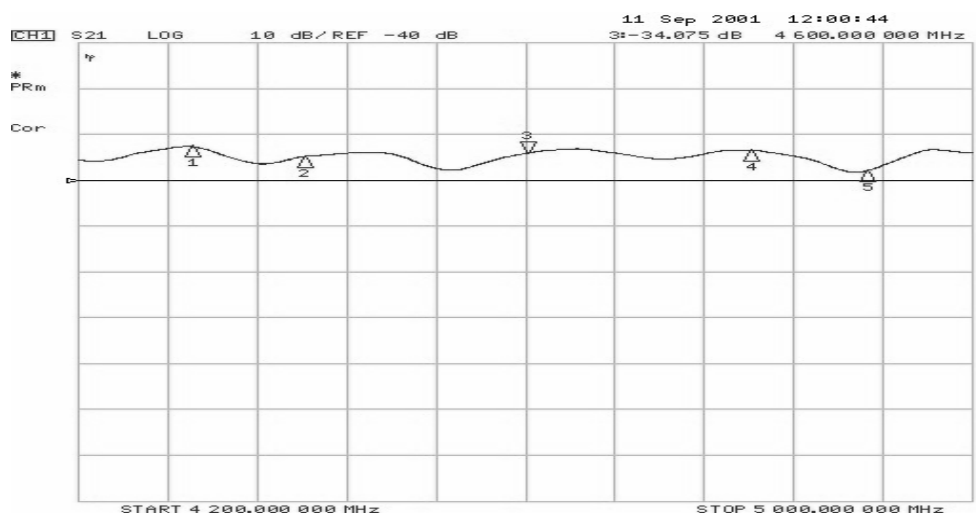

CH1 Markers

1:-32.561 $\mathrm{dB}$

2:-34. 4 .

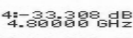

$5:-37.839 \mathrm{~dB}$
$4.90528 \mathrm{GHZ}$

(a)

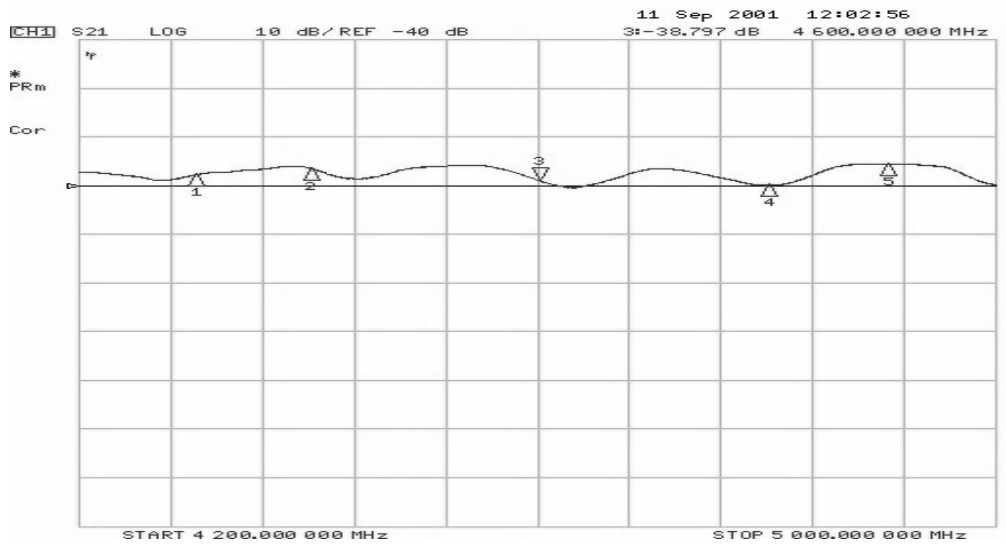

CH1 Markers

1:-37.759 $4 \mathrm{~B}$

2:-36.

4.-3ำำำำำ

$5:-35.545 \mathrm{~dB}$
$4.90528 \mathrm{GH}$

(b)

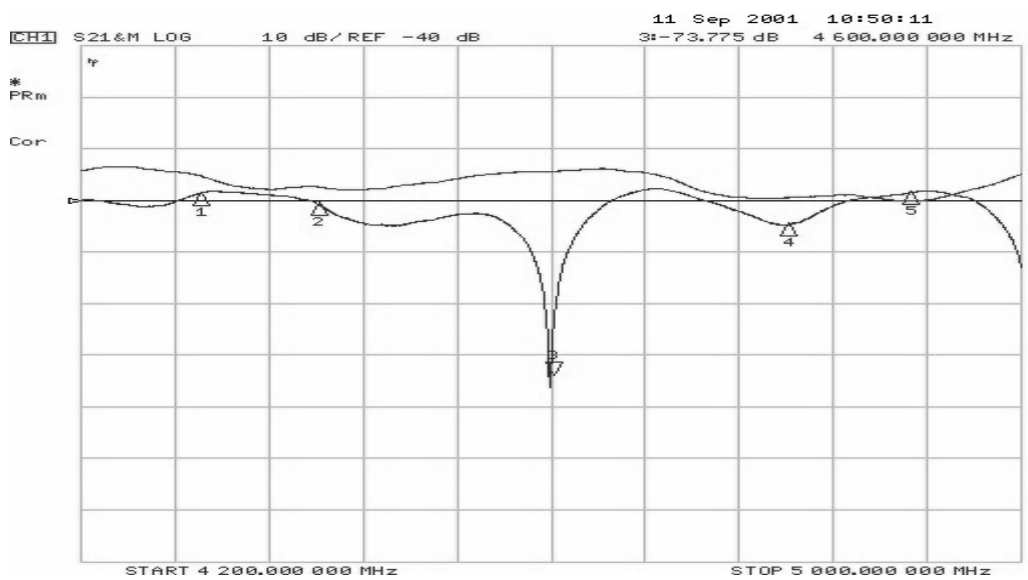

$\mathrm{CH} 1$ Markers

1:-38.454 $\mathrm{dB}$

2:-4日.28 4 .

4:-44.

$5:-38.315 \mathrm{~dB}$

(c)

Fig. 6(a): Coupling data for current loop 1 without $5 \mathrm{pF}$ (maximum) trimmer capacitor. (b): Coupling data for current loop 2 with matched length coaxial cable. (c): Composite effect of current loop 1 and loop 2 with a lab-fabricated $10 \mathrm{~dB}$ directional coupler; the data indicates that the forward path coupling (upper trace) is $-34.3 \mathrm{~dB}$ at $4.6 \mathrm{GHz}$ and the reverse path coupling (lower trace) is $-73.8 \mathrm{~dB}$ at $4.6 \mathrm{GHz}$. Thus, the directivity is $>35$ $\mathrm{dB}$ at $4.6 \mathrm{GHz}$. 


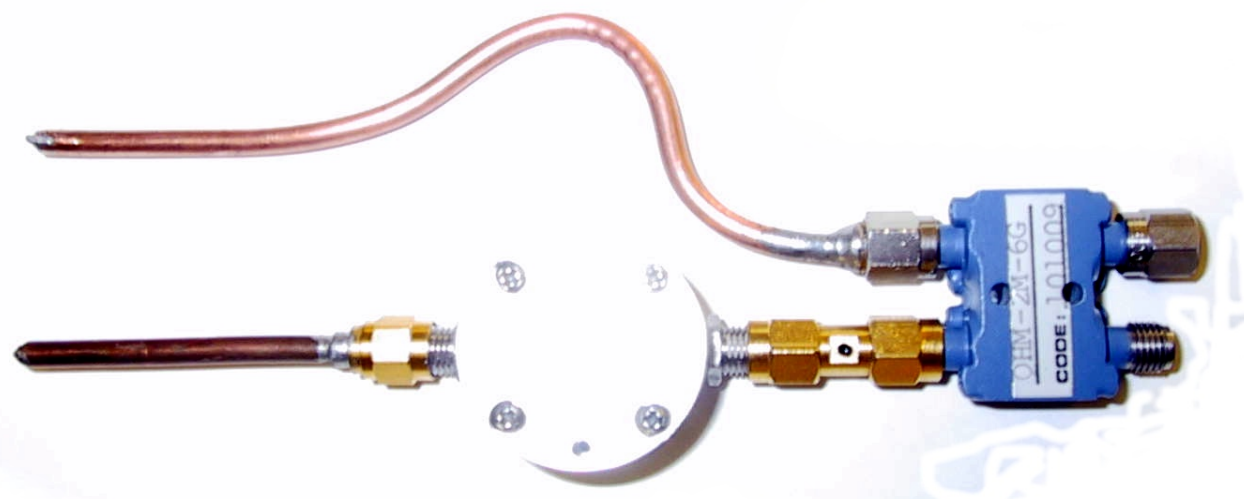

Fig. 7. Merrimac 3-dB coupler and Weinschel phase shifter are selected to build the compact probe for the MIT LHCD experiment. When loop 1 is attached to the Weinschel phase shifter through an SMA male-male adaptor, the length difference between loop 1 and loop 2 is exactly half wavelength ( 0.9 in) in this semi-rigid coaxial cable. 


\section{External Distribution}

Plasma Research Laboratory, Australian National University, Australia

Professor I.R. Jones, Flinders University, Australia

Professor João Canalle, Instituto de Fisica DEQ/IF - UERJ, Brazil

Mr. Gerson O. Ludwig, Instituto Nacional de Pesquisas, Brazil

Dr. P.H. Sakanaka, Instituto Fisica, Brazil

The Librarian, Culham Laboratory, England

Mrs. S.A. Hutchinson, JET Library, England

Professor M.N. Bussac, Ecole Polytechnique, France

Librarian, Max-Planck-Institut für Plasmaphysik, Germany

Jolan Moldvai, Reports Library, Hungarian Academy of Sciences, Central Research Institute for Physics, Hungary

Dr. P. Kaw, Institute for Plasma Research, India

Ms. P.J. Pathak, Librarian, Institute for Plasma Research, India

Ms. Clelia De Palo, Associazione EURATOM-ENEA, Italy

Dr. G. Grosso, Instituto di Fisica del Plasma, Italy

Librarian, Naka Fusion Research Establishment, JAERI, Japan

Library, Laboratory for Complex Energy Processes, Institute for Advanced Study, Kyoto University, Japan

Research Information Center, National Institute for Fusion Science, Japan

Dr. O. Mitarai, Kyushu Tokai University, Japan

Dr. Jiangang Li, Institute of Plasma Physics, Chinese Academy of Sciences, People's Republic of China

Professor Yuping Huo, School of Physical Science and Technology, People's Republic of China

Library, Academia Sinica, Institute of Plasma Physics, People's Republic of China

Librarian, Institute of Physics, Chinese Academy of Sciences, People's Republic of China

Dr. S. Mirnov, TRINITI, Troitsk, Russian Federation, Russia

Dr. V.S. Strelkov, Kurchatov Institute, Russian Federation, Russia

Professor Peter Lukac, Katedra Fyziky Plazmy MFF UK, Mlynska dolina F-2, Komenskeho Univerzita, SK-842 15 Bratislava, Slovakia

Dr. G.S. Lee, Korea Basic Science Institute, South Korea

Institute for Plasma Research, University of Maryland, USA

Librarian, Fusion Energy Division, Oak Ridge National Laboratory, USA

Librarian, Institute of Fusion Studies, University of Texas, USA

Librarian, Magnetic Fusion Program, Lawrence Livermore National Laboratory, USA

Library, General Atomics, USA

Plasma Physics Group, Fusion Energy Research Program, University of California at San Diego, USA

Plasma Physics Library, Columbia University, USA

Alkesh Punjabi, Center for Fusion Research and Training, Hampton University, USA

Dr. W.M. Stacey, Fusion Research Center, Georgia Institute of Technology, USA

Dr. John Willis, U.S. Department of Energy, Office of Fusion Energy Sciences, USA

Mr. Paul H. Wright, Indianapolis, Indiana, USA 
The Princeton Plasma Physics Laboratory is operated by Princeton University under contract with the U.S. Department of Energy.

\author{
Information Services \\ Princeton Plasma Physics Laboratory \\ P.O. Box 451 \\ Princeton, NJ 08543
}

Phone: 609-243-2750

Fax: 609-243-2751

e-mail: pppl_info@pppl.gov

Internet Address: http://www.pppl.gov 